\title{
The cyclin box and C-terminus of cyclins $A$ and $E$ specify CDK activation and substrate specificity
}

\author{
Lynn E Horton and Dennis J Templeton
}

Institute of Pathology and Program in Cell Biology, Case Western Reserve Univeristy School of Medicine 10900 E. Euclid Avenue, Cleveland, Ohio 44106, USA

\begin{abstract}
The cyclins and their catalytic partners, the $C$ yclin Dependent Kinases (CDKs), are essential for progression through the cell cycle. Cyclin/kinase complexes containing cyclins $A$ or $E$ are active primarily in late $G_{1}$ to $S$ phase and both have been shown to phosphorylate histone $\mathrm{H} 1$ and the retinoblastoma gene product $(\mathrm{pRb})$ in vitro. Despite these similarities, cyclins $A$ and $E$ display differences in CDK activation and substrate specificity. We find that in vitro, cyclin E/CDK2 and cyclin A/ CDK2 phosphorylate histone H1 similarly but only cyclin A/CDK2 phosphorylates lamin B. While both cyclin A and cyclin E bind CDK1 efficiently, only cyclin $A$ activates CDK1 kinase activity. Using chimeric proteins between cyclins $A$ and $E$ we find that both the cyclin box and $C$-terminus of cyclins $A$ and $E$ are required for $\mathrm{CDK}$ binding, activation and targeting of substrate specificity.
\end{abstract}

Keywords: cell cycle; cyclins; cyclin dependent kinase; lamin B

\section{Introduction}

Cell cycle transitions in mammalian cells are regulated by complex pathways involving multiple cell cycle kinases (CDKs) and kinase regulatory proteins (cyclins). Early studies on CDKs using yeast as a model system demonstrated that two important checkpoints in the cell cycle, entry into $\mathrm{S}$ phase and mitosis, were controlled by the cdc2/CDC28 kinase (hereafter called CDK1, reviewed in (Naysmith, 1993). CDK1 is also a component of maturation promoting factor (MPF) and appears in higher eukarocytes to primarily control mitotic events (reviewed in Hunt, 1989). Through complementation studies in yeast a second human cyclin dependent kinase was discovered, CDK2 (Elledge and Spottswood, 1991). Although CDK2 can compliment a null mutation of cdc2 in yeast, the apparent role for CDK2 in humans is at the $G_{1} / S$ phase boundary (Elledge et al., 1992; Fang and Newport, 1991; Pagano et al., 1993; Rosenblatt et al., 1992; Tsai et al., 1993).

The cyclins were first identified in invertebrate embryos as proteins whose concentration fluctuated during the cell cycle (Hunt, 1989). The cyclins identified so far fall into three families, the $G_{1}$ cyclins (D1, D2, D3 and E), the S phase cyclin A and the $\mathrm{G}_{2} /$ M cyclin B, (Sherr, 1993). Cyclin A/CDK1 also

Correspondence: DJ Templeton

Received 24 May 1996; revised 30 September 1996; accepted 1 October 1996 contains an MPF-like activity, arguing that cyclin A has roles in both $S$ phase and a cyclin B-like role in $G_{2} /$ M (Sherr, 1993; Pines, 1993). Cyclin B has been shown to contain a nuclear localization signal near the amino terminus that is lacking in cyclins $\mathrm{A}$ and $\mathrm{E}$ (Pines and Hunter, 1994).

All classes of cyclins share a limited homology in a region termed the cyclin box which, for cyclin $\mathrm{A}$, has been shown to be required to bind the kinase (Hunt, 1991; Kobayashi et al., 1992; Lees and Harlow, 1993). However, the binding of cyclin to kinase may not appear to be sufficient for activation of the kinase (Ducommun et al., 1991). Cyclins A and E retain the highest identity of all cyclin members throughout their cyclin box domains (Hunt, 1991; Nugent et al., 1991). The two cyclin proteins have been shown to bind to both CDK1 and CDK2 (Koff et al., 1991; Pines, 1993; Rosenblatt et al., 1992; Roy et al., 1991). Peaks in protein levels and associated kinase activities of cyclins $A$ and $E$ overlap significantly through late $G_{1}$ and early S phase (Dulic et al., 1992; Koff et al., 1991, 1992; Pines, 1993). Microinjection of either cyclin A or cyclin E mRNA, or overexpression of either protein, causes premature entry into $\mathrm{S}$ phase (Girard et al., 1991; Quelle et al., 1993; Resnitzky et al., 1994, 1995). Both cyclin/kinase complexes phosphorylate histone $\mathrm{H} 1$ and the retinoblastoma susceptibility gene product $(\mathrm{pRb})$ in vitro, although the E/CDK1 complex only weakly phosphorylates histone H1 (Hinds et al., 1992; Horton et al., 1995; Koff et al., 1992; Pines and Hunter, 1991).

Despite similar binding partners, overlapping expression and the ability to promote $\mathrm{S}$ phase entry there are important differences in the abilities of cyclins A and E to activate kinase and recognize substrate. Corresponding to the $\mathrm{G}_{2}$ expression of cyclin $\mathrm{A}$, it forms a highly active complex with CDK1, whereas cyclin E only minimally activates CDK1 (Koff et al., 1991). Cyclin A/CDK complexes are more active in phosphorylating an $\mathrm{S}$ phase substrate DP-1 than cyclin E/CDK (Dynlacht et al., 1994). More recently the tumor suppressor p53 has been shown to be a substrate of cyclin A/CDK2 but not E/ CDK2 (Wang and Prives, 1995).

We show here that lamin B is phosphorylated by cyclin $\mathrm{A} / \mathrm{CDK}$ and is not recognized by cyclin $\mathrm{E} / \mathrm{CDK}$ in vitro. Additionally, cyclin $\mathrm{A}$, but not cyclin $\mathrm{E}$, activates CDK1. We constructed a panel of chimeric proteins between the two cyclins, using regions of identity to interchange major domains of each of the cyclin proteins. Each of the cyclins are dependent on native cyclin box and $\mathrm{C}$ terminal domains to bind and activate CDKs. Despite the functional similarities of cyclins $\mathrm{A}$ and $\mathrm{E}$, disruption of their native $\mathrm{C}$ terminal domains (including the cyclin box and $\mathrm{C}$-termini) results in inability to bind 
kinase. N-terminal domain swaps between the cyclins yielded no change in substrate recognition or kinase activation compared to wild type cyclin proteins. Therefore we ascribe the lamin $\mathrm{B}$ substrate recognition and kinase activation of the cyclin/CDK complex to the cyclin box-C-terminus of the protein.

\section{Results}

\section{Construction of cyclin $A$ and $E$ chimeras}

Cyclins A and E are highly homologous in their cyclin box domains but show limited homology outside of the cyclin box (Hunt, 1991). Since cyclins A and E are thought to bind CDK1 and CDK2 through their cyclin boxes, but differ in kinase activities toward E2F/DP-1, p53 and lamin B, we hypothesized that cyclins target CDKs to specific substrates via sequences either in the $\mathrm{N}$-terminal or C-terminal domains of the cyclin molecules. To determine domains on cyclins $\mathrm{A}$ and $\mathrm{E}$ that are essential for kinase binding, activation and substrate targeting we constructed chimeric proteins between cyclins $\mathrm{A}$ and $\mathrm{E}$. The fusion sites and resultant chimeric proteins are shown in Figure 1. We used epitope tagged versions of these chimeras so that all could be analysed with the same monoclonal antibody (termed anti-EE) and protein levels on Western blots could be directly compared.

Chimeras were tested for ability to bind CDK2 and for histone $\mathrm{H} 1$ kinase activity. Results are summarized in Figure 1. The AEE chimera made at the 184/111
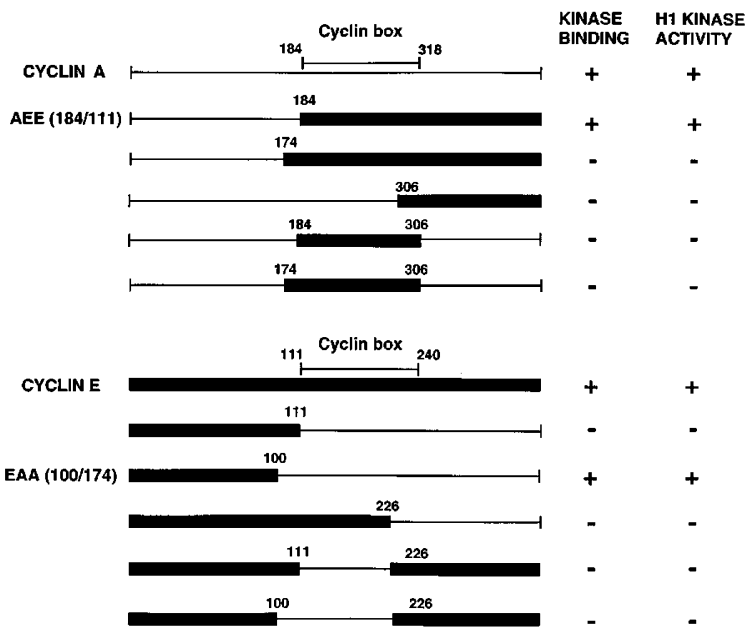

Figure 1 Schematic diagram depicting the construction of chimeric cyclin genes and the resulting chimeric cyclin proteins. Points of fusion are represented by the amino acid number of cyclins $\mathrm{A}$ and $\mathrm{E}$. Cyclin $\mathrm{A}$ is represented by a thin line and cyclin $\mathrm{E}$ by a thick line. Location of the cyclin box is shown over cyclin A and cyclin E. Kinase binding and histone H1 activity measured for each of the constructed chimeras is shown in a panel to the right of the diagrams. All chimeras diagrammed were expressed successfully, but most lacked kinase binding and H1 kinase activity. Only cyclin chimeras AEE (184/ $111)$ and EAA (100/174) retained activity; these chimeras are described in further experiments. 'AEE' refers to the molecule containing the Amino terminus of cyclin $\mathrm{E}$, and the cyclin box and C-terminus of cyclin $\mathrm{E}$ (amino acid junctions denoted above). 'EAA' refers to the opposite molecule, with only the amino terminus of cyclin $\mathrm{E}$ fusion site and the EAA chimera made at the 100/174 fusion site were functional in binding $\mathrm{CDK}$ and phosphorylating histone (Figure 1, see also Figures $3 \mathrm{a}$ and $4 \mathrm{a}$ ). Chimeras exchanging the $\mathrm{C}$ terminus of the cyclins and those exchanging the cyclin boxes were all non-functional in binding CDK and phosphorylating histone $\mathrm{H} 1$ (data not shown). We cannot exclude trivial explanations such as aberrant protein folding and destruction of three dimensional structure for the lack of activity of the non-functional chimeras.

\section{Lamin $B$ is phosphorylated by cyclin $A$ but not cyclin $E$}

In a search for cyclin/kinase specific substrates we tested lamin B, a known substrate of cyclin B/CDK1. We compared the ability of cyclin $\mathrm{B} / \mathrm{CDK} 1$, cyclin $\mathrm{A} /$ CDK2 and cyclin $\mathrm{E} / \mathrm{CDK} 2$ to phosphorylate lamin $\mathrm{B}$ (Figure 2). In addition to phosphorylation by cyclin B/ CDK1, lamin $\mathrm{B}$ is phosphorylated by CDK2 in conjunction with cyclin A (Figure 2 and see also Figure 3b). However, the cyclin E/CDK2 kinase complex is unable to phosphorylate lamin $\mathrm{B}$. The timing of lamin B phosphorylation within the cell cycle correlates with the timing of the cyclin A/CDK1 complex, rather than the cyclin $\mathrm{A} / \mathrm{CDK} 2$ complex. Thus, it is likely that cyclin A/CDK1, along with cyclin $\mathrm{B} / \mathrm{CDK} 1$, may be the physiological lamin $\mathrm{B}$ kinase complex. Moreover, this result identifies a new substrate specific for cyclin A.

\section{The cyclin box and cyclin $C$-terminus determines substrate specificity}

We next tested whether the $\mathrm{N}$ terminus or the cyclin box/C terminus of the cyclins was necessary for substrate specificity in conjunction with the CDK2 kinase. In our initial studies we found that cyclins A and $\mathrm{E}$ phosphorylated histone $\mathrm{H} 1$ equally. To control for variability in separate kinase preparations we tested each of the cyclin/CDK preparations on histone $\mathrm{H} 1$. For each experiment we pre-tested each preparation of histone $\mathrm{H} 1$ phosphorylation and used equivalent $\mathrm{H} 1-$ phosphorylation units when testing the cyclin/kinases on GST-pRb-large pocket (GST-Rb-LP) and bacte-

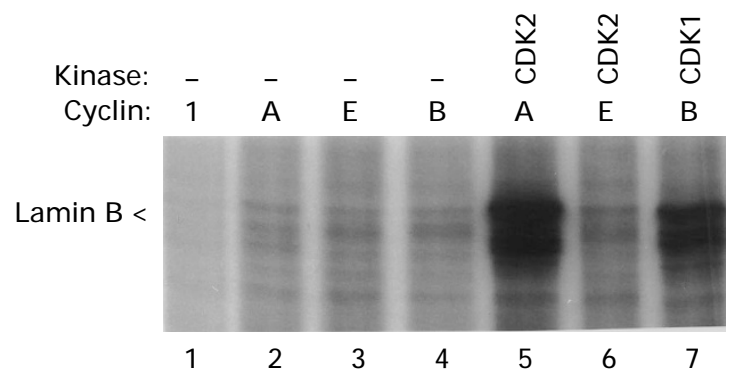

Figure 2 Phosphorylation of lamin B in vitro by purified cyclin/ CDK combinations. Lamin B purified from rat liver nuclear envelopes was reacted with anti-epitope purified proteins from mock transfected cells (lane 1), epitope tagged cyclin A (lane 2), cyclin E (lane 3 ) or cyclin B (lane 4) without added CDK, or with epitope tagged cyclin A/CDK2 (lane 5), cyclin E/CDK2 (lane 6) or cyclin B/CDK1 (lane 7 ) in the presence of $\left[\gamma^{32} \mathrm{P}\right] \mathrm{ATP}$. CDK's in this study do not contain the epitope tag, and purify on the basis of their association with epitope tagged cyclin. Cyclin A/ CDK2 and cyclin $\mathrm{B} / \mathrm{CDK} 1$ both phosphorylate lamin B dependent on the presence of kinase, whereas cyclin E/CDK2 is unable to phosphorylate lamin B. Exposure time was $3 \mathrm{~h}$ 
a

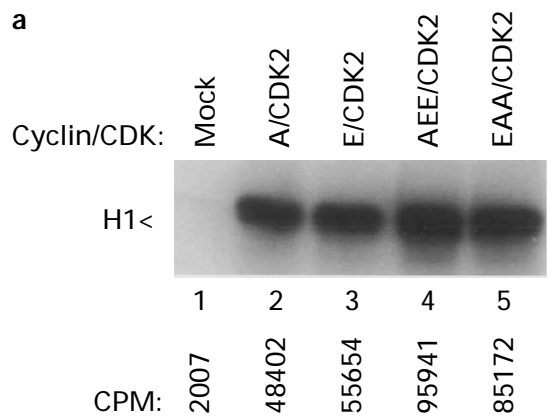

c

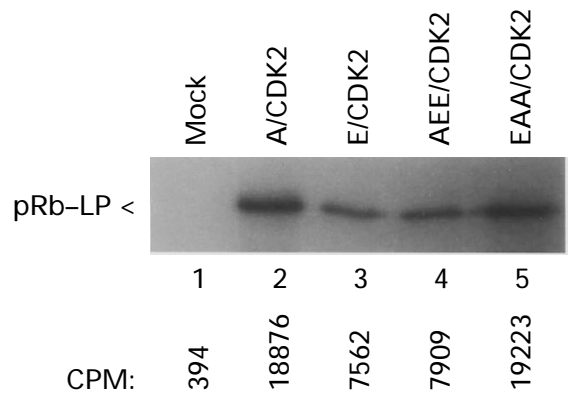

b
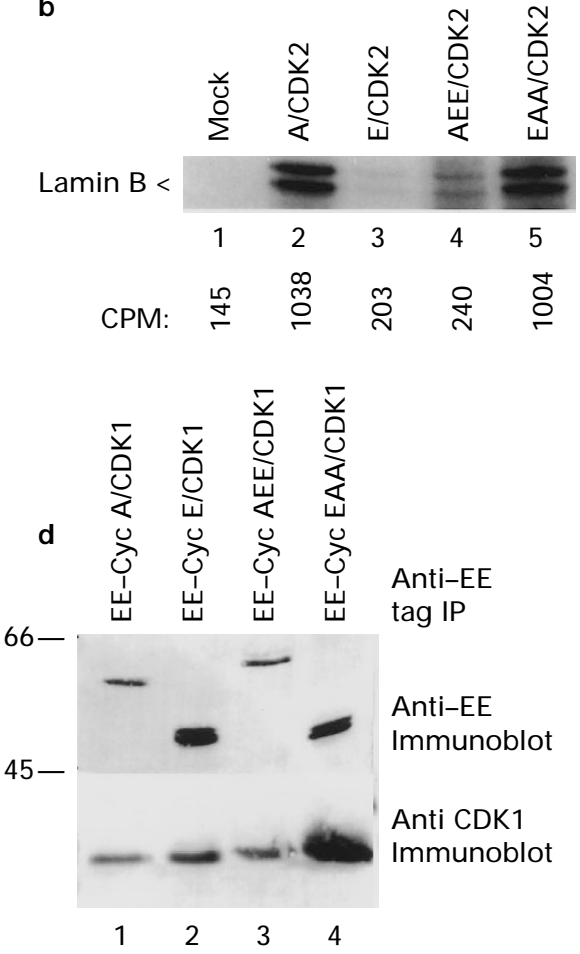

Figure 3 Phosphorylation of histone H1, pRb and lamin B by the cyclin and cyclin chimeras in complex with CDK2. A, $0.5 \mu \mathrm{g}$ histone $\mathrm{H} 1$ was reacted with a mock extract (lane 1), cyclin A/CDK2 (lane 2), cyclin E/CDK2 (lane 3), cyclin AEE/CDK2 (lane 4) or cyclin EAA/CDK2 (lane 5) in the presence of $\left[\gamma^{32} \mathrm{P}\right] \mathrm{ATP}$. Histone $\mathrm{H} 1$ incorporation of radiolabeled phosphate was quantified using an AMBIS $\beta$-detector, subtracting the incorporation in the Mock lane. The quantification is shown below each lane on the autoradiograph (lower panel). Exposure time for the autoradiogram was $10 \mathrm{~min}$. (b) as in (a) but using 50 ng of bacteriallyexpressed lamin B. Exposure time for the autoradiogram was 2 h. (c) as in a but using 50 ng GST-Rb-LP. Exposure time for the autoradiogram was $1 \mathrm{~h}$. (d) (top) Expression of cyclins and chimeric cyclins was tested by immunoblotting the purified kinase preparations using anti-EE epitope tag antibody. (d) (bottom) The presence of complexed CDK2 in the kinase preparations was confirmed by immunoblotting using polyclonal anti-CDK2 antibody (UBI)

rially produced lamin $\mathrm{B}$ substrates (see Materials and methods). The bacterial lamin $\mathrm{B}$, recognized by $\mathrm{a}$ monoclonal lamin B antibody, migrated as a doublet and both bands were quantified together (Figure $3 \mathrm{~b}$ and data not shown). Cyclins $\mathrm{A} / \mathrm{CDK} 2$ and $\mathrm{E} / \mathrm{CDK} 2$ phosphorylated both GST-Rb-LP (Figure 3c) and lamin B (Figure 3b) differentially despite their equivalent kinase activities towards histone $\mathrm{H} 1$. Phosphorylation of $\mathrm{pRb}$ by cyclin $\mathrm{E} / \mathrm{CDK} 2$ was about $40 \%$ that of cyclin $\mathrm{A} / \mathrm{CDK} 2$, while phosphorylation of lamin $\mathrm{B}$ by cyclin $\mathrm{E} / \mathrm{CDK} 2$ was essentially nil. Using the cyclin chimeras we determined the region of the cyclin which confers substrate specificity.

Cyclins $\mathrm{A} / \mathrm{CDK} 2$ and EAA/CDK2 both phosphorylated lamin B with equal efficiency, while cyclins $\mathrm{E} /$ $\mathrm{CDK} 2$ and $\mathrm{AEE} / \mathrm{CDK} 2$ respectively phosphorylated lamin B at least sixfold less efficiently. A similar result was obtained using lamin B isolated from nuclear envelopes (see Figure 2 and data not shown). GST-RbLP was also differentially phosphorylated by the cyclin/ CDKs and followed the pattern seen with the lamin $B$ substrate (Figure 3b). Like cyclin A/CDK2, cyclin EAA/ CDK2 showed a higher kinase activity towards $\mathrm{pRb}$ than did cyclin E/CDK2 or AEE/CDK2 (Figure 3c, lane 5).

Immunoblotting confirmed equivalent recoveries of cyclins E, AEE and EAA from experiments in which the cyclins were co-expressed with CDK2 (Figure 3d). Cyclin A recovery was reduced compared to the recovery of the other cyclins. However all cyclins efficiently co-immunoprecipitated the co-expressed
CDK2 (Figure 3d). Although the levels of cyclin expression varied, the ratio of cyclin to kinase was the same for all cyclin/kinase preparations. In time course experiments (not shown), phosphorylation of Histone $\mathrm{H} 1$ by each of the cyclin/CDK2 combinations proceeded linearly and equivalently for $10 \mathrm{~min}$, while cyclin E/CDK2 and cyclin AEE/CDK2 complexes phosphorylated lamin $\mathrm{B}$ at only one-sixth the rate of $\mathrm{A} / \mathrm{CDK} 2$ and $\mathrm{EAA} / \mathrm{CDK} 2$.

\section{Specific requirement for cyclin $A$-terminus for $C D K 1$ activation}

While both cyclin A and cyclin E can activate CDK2, we found that cyclin $\mathrm{E}$ is unable to cooperate with $\mathrm{CDK} 1$ (i.e. cdc2). The reaction of cyclins A, E, AEE and EAA together with CDK1 in an in vitro kinase assay is shown using histone $\mathrm{H} 1$ (Figure 4a), pRb (Figure 4c) and lamin $\mathrm{B}$ (Figure $4 \mathrm{~b}$ ) as substrates. Cyclins $\mathrm{A} / \mathrm{CDK} 1$ and EAA/ CDK1 both efficiently phosphorylated $\mathrm{H} 1, \mathrm{pRb}$ and lamin $\mathrm{B}$ in vitro, while cyclin $\mathrm{E} / \mathrm{CDK} 1$ and $\mathrm{AEE} / \mathrm{CDK} 1$ complexes contain minimal activity towards $\mathrm{H} 1, \mathrm{pRb}$ and lamin $\mathrm{B}$ substrates in vitro (Figure $4 \mathrm{a}, \mathrm{b}$ and $\mathrm{c}$ ). Phosphorylation of $\mathrm{pRb}$ was determined both by incorporation of $\left[{ }^{32} \mathrm{P}\right]$ into $\mathrm{pRb}$, as well as by the appearance of a mobility shift characteristic of phosphorylation evident on Western blot (Figure 4c). Immunoblotting confirmed equivalent recoveries of cyclins E, AEE and EAA and their association with coexpressed CDK1 (Figure 4d). Cyclin A recovery was 

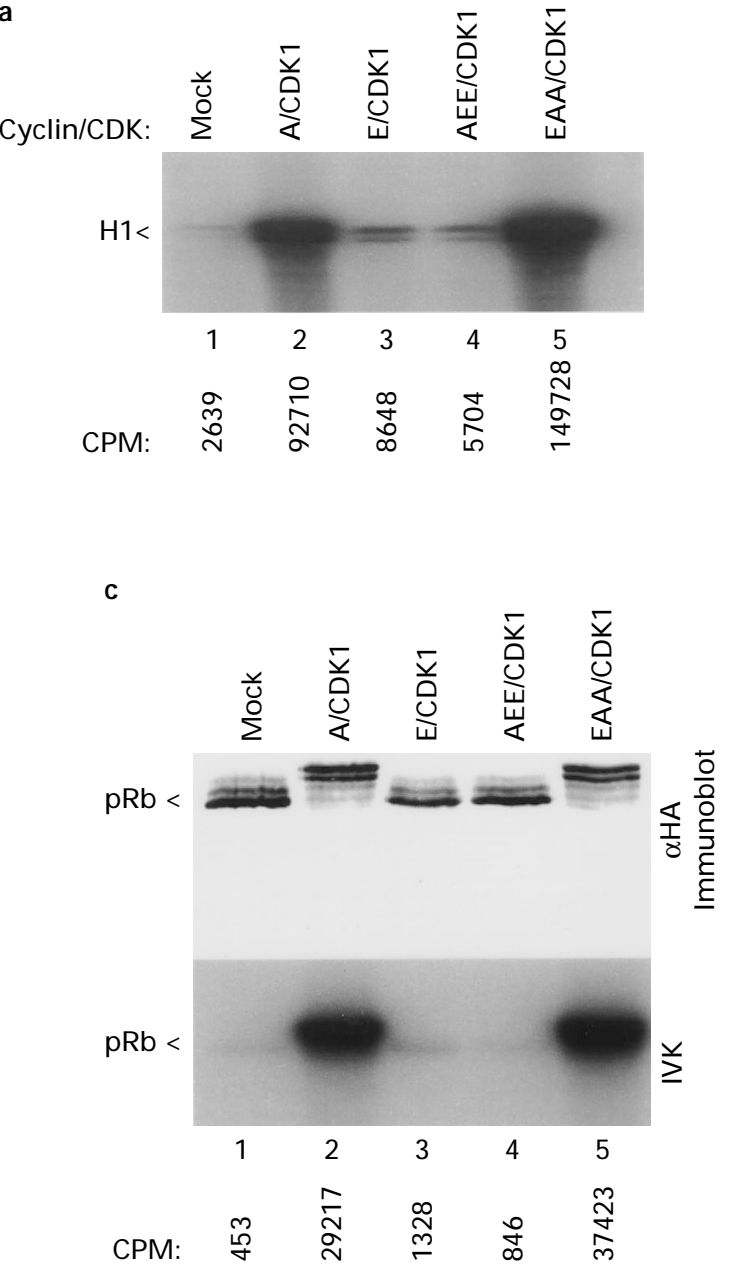



d

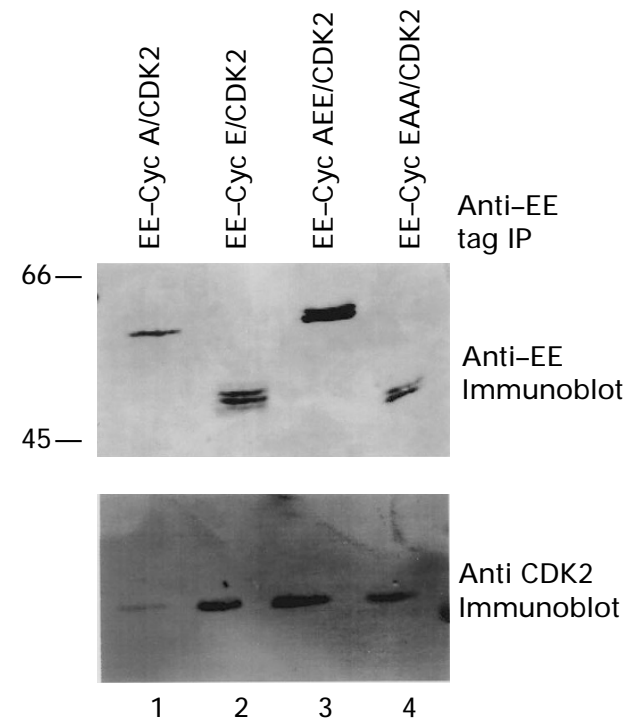

Figure 4 Phosphorylation of histone H1, pRb and lamin B by the cyclin and cyclin chimeras in complex with CDK1. (a) $0.5 \mu \mathrm{g}$ histone $\mathrm{H} 1$ was reacted with a mock extract (lane 1), cyclin A/CDK1 (lane 2), cyclin E/CDK1 (lane 3), cyclin AEE/CDK1 (lane 4) or cyclin EAA/CDK1 (lane 5) in the presence of $\left[\gamma^{32} \mathrm{P}\right] \mathrm{ATP}$. CDK proteins are not epitope tagged. Histone $\mathrm{H} 1$ incorporation of radiolabeled phosphate was quantified by AMBIS. The quantification is shown below the appropriate lane on the autoradiograph. Exposure time for the autoradiogram was $10 \mathrm{~min}$. (b) same as a but using lamin B isolated from rat liver nuclear envelopes. Exposure time for the autoradiogram was $16 \mathrm{~h}$. (c) as in a but using immunopurified $\mathrm{pRb}$. Exposure time for the autoradiogram was $1 \mathrm{~h}$. (d) (top) Expression of cyclins and chimeric cyclins was tested by immunoblotting the purified kinase preparations using anti-EE epitope tag antibody. (d) (bottom) The presence of complexed CDK1 in the kinase preparations was confirmed by immunoblotting using polyclonal anti-CDK1 antibody (GIBCO-BRL)

again reduced compared to the recovery of the other cyclins, as is the co-immunoprecipitated CDK1 (Figure 4d). Although the levels of cyclin expression varied, the ratio of cyclin to kinase was again the same for all cyclin/ kinase preparations.

Thus, cyclin $\mathrm{A} / \mathrm{CDK} 1$ and cyclin EAA/CDK1 complexes efficiently phosphorylate histone $\mathrm{H} 1$, while the cyclin E/CDK1 and AEE/CDK1 complexes lack significant kinase activity towards histone $\mathrm{H} 1$. Neither the $\mathrm{N}$ terminus of cyclin $\mathrm{A}$ nor the cyclin box/C terminus of cyclin $\mathrm{E}$ is sufficient to activate $\mathrm{CDK} 1$ in our assay.

Binding of cyclin $E$ retains binding to $C D K 1$ even in the presence of $C D K 2$

As shown above, cyclin E associates with CDK1, but this cyclin-kinase complex is inactive. The reason for the cyclin $\mathrm{E} / \mathrm{CDK} 1$ inactivity is unclear. As a control to demonstrate that the non-productive binding of cyclin $\mathrm{E}$ to $\mathrm{CDK} 1$ was detected specifically, we again measured the binding of cyclins A and E to CDK1. We overexpressed CDK1 (without epitope tag) either alone or with epitope tagged cyclin A or cyclin E (Figure 5). In an additional experiment, we provided CDK2 by coexpression, to determine if CDK2 might easily displace the non-functional CDK1 from cyclin E. No CDK1 immunoreactivity is detected without transfection of the CDK1 expression plasmid (lane 2) since exogenously produced CDK1 is not recognized by the epitope tag antibody. Equal amounts of CDK1 is associated with both cyclins $\mathrm{A}$ and $\mathrm{E}$ (lanes 3 and 5), and the association of both cyclins $\mathrm{A}$ and $\mathrm{E}$ with $\mathrm{CDK} 1$ is only partially reversed by coexpression of CDK2 (lanes 4 and 6). Thus the relative affinity of both cyclin $A$ and $\mathrm{E}$ with $\mathrm{CDK} 1$ is roughly equivalent despite the inability of cyclin $\mathrm{E} / \mathrm{CDK} 1$ to form an active kinase in this system. 


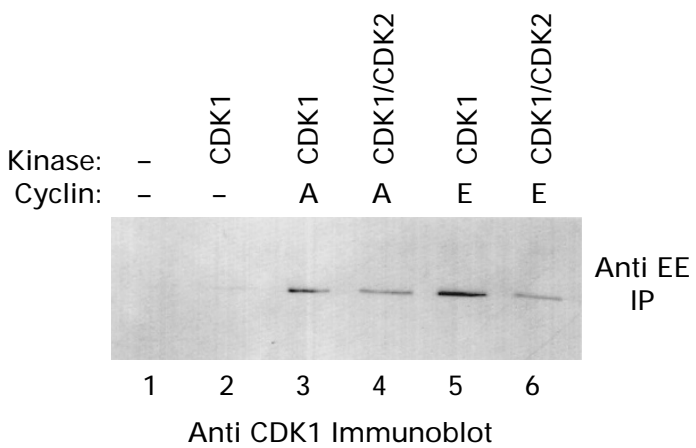

Figure 5 Cyclins A and E equally associate with CDK1. Anti-EE epitope immune complexes from mock-transfected cells (lane 1) or cells expressing untagged CDK1 (lane 2) or CDK1 together with cyclin A (lane 3) or cyclin E (lane 5) were tested for CDK1 binding by immunoblotting using anti-CDK1 serum. Parallel cultures expressing both CDK1 and CDK2 retained similar, slightly reduced, binding of both cyclin A and cyclin E to CDK1 (lanes 4 and 6)

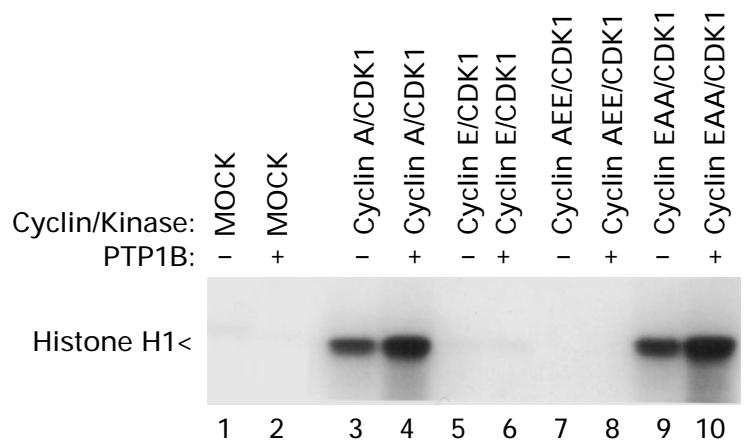

Figure 6 Treatment with a tyrosine phosphatase enhances the histone $\mathrm{H} 1$ kinase activity of cyclin $\mathrm{A} / \mathrm{CDK} 1$ and cyclin EAA CDK1 but not cyclin $\mathrm{E} / \mathrm{CDK} 1$ or $\mathrm{AEE} / \mathrm{CDK} 1$. Immunopurified cyclin/CDK1 was treated with either kinase buffer alone (odd numbered lanes) or with PTP1B (even numbered lanes) for $30 \mathrm{~min}$. Phosphatase reactions were stopped by addition of $1 \mathrm{~mm}$ sodium orthovanadate and $10 \mathrm{~mm}$ PNPP. In vitro histone $\mathrm{H} 1$ kinase assays of treated and untreated samples were then performed by addition of $0.5 \mu \mathrm{g}$ of $\mathrm{H} 1$ and $10 \mu \mathrm{Ci}\left[\gamma^{32} \mathrm{P}\right] \mathrm{ATP}$ Samples were analysed using $12.5 \%$ SDS-PAGE

The inactivity of cyclin E/CDK1 complexes is not due to tyrosine phosphorylation of $C D K 1$

Despite the ability of cyclin E and cyclin AEE to bind CDK1 kinase, these complexes do not form active kinase complexes. Cyclin/kinase complexes can be inhibited by phosphorylation of a conserved tyrosine residue (amino acid 15 in CDK1 and CDK2), within the ATP binding domain of the kinase, and this can be reserved by the cdc25 phosphatase (Solomon, 1993). The inactive cyclin $\mathrm{E} / \mathrm{CDK} 1$ complex may be inactive because it is inhibited by quantitative phosphorylation within the ATP binding domain possibly because cyclin $\mathrm{E} / \mathrm{CDK} 1$ fails to recruit the necessary phosphatase to dephosphorylate this residue. However, CDK1 coimmunoprecipitated with cyclin E demonstrated undetectable levels of phosphotyrosine, shown by both anti-phosphotyrosine immunoblot and phosphoamino analysis of ${ }^{32} \mathrm{P}$-labeled proteins (data not shown). In addition treatment of the cyclin/kinase complex with a tyrosine specific phosphatase, PTP1B did not increase cyclin $\mathrm{E} / \mathrm{CDK} 1$ or cyclin $\mathrm{AEE} / \mathrm{CDK} 1$ activity towards histone $\mathrm{H} 1$ (Figure 6, lanes 5, 6, 7 and 8). In contrast to the lack of effect on cyclins E and AEE, cyclin A/ CDK1 and EAA/CDK1 activity towards histone H1 increased after treatment with PTP1B, ostensibly because a fraction of the CDK1 contains the inhibitory tyrosine phosphorylation (Figure 6, lanes 3 and 4,9 and 10). We conclude that the absence of cyclin $\mathrm{E} / \mathrm{CDK} 1$ activity in vitro is not due to an inhibitory tyrosine phosphorylation on CDK1.

\section{Discussion}

Cyclin A and cyclin E differ in their ability to form a functional kinase complex with CDK1 and CDK2. The ability to activate CDK1 is specific to cyclin A and demonstrates that the activation of all CDKs is dependent upon more than simple cyclin association. One such possibility is that the cyclins may act to recruit necessary activating factors, as is the case with cyclin B and cdc25 (Solomon, 1993). We have shown that dephosphorylation of the inactive $\mathrm{CDK} 1 /$ cyclin $\mathrm{E}$ complex with PTP1B is unable to restore activity. Thus, phosphorylation of CDK1 phosphorylation on tyrosine 15 is unlikely to be the mechanism that prevents cyclin E/CDK1 complexes. Recent studies have shown that the cyclin E/CDK1 complex can be phosphorylated by the CDK activating CAK kinase on threonine 161 of CDK1, but that this is insufficient for activation of the kinase (Desai et al., 1995). This result is compatible with our findings.

Analysis of our cyclin chimeras has partially localized the ability to activate specific kinases to a portion of the cyclin molecule. The chimeric cyclins retained the ability to activate CDK1 in every instance that the cyclin box and $\mathrm{C}$-terminus of cyclin $\mathrm{A}$ was preserved. Likewise those chimeras with the cyclin box and $\mathrm{C}$-terminus of cyclin $\mathrm{E}$ could activate CDK2, but not CDK1. Therefore these domains function to provide the specific activation of the bound CDK, while the amino terminus of the cyclin must contribute uncharacterized properties. This is in close agreement to previous findings in which the amino terminal domains of cyclin A were unnecessary for CDK binding and activation of histone $\mathrm{H} 1$ kinase activity (Kobayashi et al., 1992; Lees and Harlow, 1993). Many other chimeric cyclin molecules were prepared that segregated different segments of the cyclin molecules. Despite construction of the fusion proteins based on areas of high homology, none but those with intact cyclin box and C-termini retained the ability to bind and activate kinase. We conclude that precise structural conformation of the cyclins must be important for retention of the ability to bind and activate kinase.

We have identified lamin B as substrate specific for cyclin A. Despite equivalent histone $\mathrm{H} 1$ kinase activities of both cyclins $\mathrm{A} / \mathrm{CDK} 2$ and $\mathrm{E} / \mathrm{CDK} 2$, cyclin $\mathrm{E} / \mathrm{CDK} 2$ complexes are unable to phosphorylate lamin B. The specificity of cyclin $\mathrm{A} / \mathrm{CDK}$ for lamin $\mathrm{B}$ is in concert with the model that phosphorylation of lamin B by CDK is an event required for nuclear envelope breakdown preceding mitosis (McKeon, 1991). Since cyclin A/CDK activity extends 
well into $G_{2}$, this temporal peak of activity coincides with the anticipated timing of nuclear envelope protein phosphorylation. It might be expected that should $\mathrm{G}_{1}$ cyclins phosphorylate lamin $\mathrm{B}$, the cell might undergo premature mitotic events, such as the premature chromatin condensation associated with mutation of the RCC1 gene (Uchida et al., 1990).

Similar to the ability of the cyclin box and Cterminus of cyclins to specify CDK utilization, analysis of our cyclin chimeras demonstrated that the cyclin box and C-terminus of cyclin A provides the specificity of substrate recognition to $\mathrm{CDK} 2$. The fact that it is the cyclin moiety of the cyclin/CDK complex that identifies substrate rather than the CDK itself is in conflict with the generally accepted model for substrate binding by kinases. The crystallographic structures of CDK2 (De-Bondt et al., 1993; Jeffrey et al., 1995), MAP kinase (Zhang et al., 1993) and PKA (Zheng et al., 1993), have shown that these kinases are similar in containing a polypeptide loop that obstructs access to the substrate binding domain. These and many other kinases are activated at least in part by phosphorylation of residues within these domains (e.g. thr 160 on CDK2, and thr 183 and tyr 185 on MAP kinase) which can be seen as altering the conformation of the loop to provide access (Marshall, 1994; Taylor et al., 1993). If this model is accurate, the recognition of specific substrates by different kinases should lie within the realm of the kinase.

Binding of CDK's by cyclins offers an additional level of control over the operation of the activation loop and the substrate binding pocket, as shown by the recent crystal structure of CDK2 bound to a fragment of cyclin A (Jeffrey et al., 1995). This structure has revealed that cyclin A binding folds open the activation loop to two effects: first, to allow access to substrate (and approximation of the substrate to the $\gamma$-phosphate of the bound ATP), and second to shift the thr 160 within the loop to the surface where it can be phosphorylated by CAK, presumably opening the substrate binding pocket further.

Our data provides functional confirmation of some of the predictions made by the crystal structure, in the binding of the cyclin box and C-terminus of the cyclin (similar to the cyclin fragment co-crystallized with CDK) specifies the nature of the substrate recognized by the CDK-cyclin complex. Binding of specific cyclins must result in conformations that allow highly specific substrate recognition beyond the level provided by the basic CDK consensus phosphorylation motif (P-S/T-Xbasic). While all cyclin-CDK2 molecules recognize this core motif (as reflected by the shared ability to phosphorylate histone $\mathrm{H} 1$ and $\mathrm{pRb}$ ), only the precise conformation afforded by cyclin A binding allows the higher level of specificity required to recognize lamin $\mathrm{B}$ as substrate. If substrates specific to cyclin E/CDK complexes exist, they have yet to be identified.

We have, through the use of chimeric proteins, defined a role for the cyclin box and C-terminus of the cyclin protein. That role is to target specificity of both CDK activation and substrate recognition. We have also defined a new cyclin A/CDK specific substrate, lamin $\mathrm{B}$, and have clarified the mechanism by which kinase recognizes substrate. Through further study of individual cyclin/CDK complexes and by further elucidation of cyclin specific CDK substrates we will gain a better understanding of the unique role each cyclin/CDK plays in promoting cell cycle progression.

\section{Materials and methods}

\section{Cell culture}

CV1 cells were maintained in high-glucose DMEM supplemented with $10 \%$ bovine calf serum and antibiotics.

\section{Plasmids}

Construction of the CDK1-TM1, CDK2-TM1, cyclin A$5^{\prime} \mathrm{EE} \mathrm{TM} 1$, cyclin E-5'EE TM1 and $\mathrm{pRb}-5^{\prime} \mathrm{HA}$ TM1 as described elsewhere (Horton et al., 1995). A cDNA for lamin $\mathrm{B}$ was cloned into the pET bacterial expression vector (Novagen). Large pocket $\mathrm{pRb}$-GST was a gift from Bill Kaelin (Dana Farber Cancer Institute, Boston, MA). The chimeric cyclin mutants were created using site directed mutagenesis using a variation of the 'mega primer mutagenesis' (Sarkar and Sommer, 1990). In our variation primers containing the $5^{\prime}$ sequence of one cyclin and $3^{\prime}$ sequence of the opposing cyclin were made, encoding amino acid sequences common to both cyclins (see also Figure 1). 'AEE' refers to the molecule containing the Amino terminus of cyclin E, and the cyclin box and Cterminus of cyclin E. 'EAA' refers to the opposite molecule, with only the amino terminus of cyclin E.

\section{Expression and isolation of proteins}

We used the vaccinia virus/T7 polymerase expression system to express cyclins and kinases (Elroy-Stein et al., 1989; Moss et al., 1990). While this system provides unnaturally high levels of protein expression, most posttranslational processes (e.g. phosphorylation and nuclear translocation) proceed at apparently normal levels (Horton et al., 1995; Qian et al., 1992; Templeton, 1992). Approximately $2 \times 10^{7} \mathrm{CV} 1$ cells were starved $24 \mathrm{~h}$ before infection in $0.2 \%$ calf serum, then infected with vaccinia virus vector vTF7-3 (Moss et al., 1990) encoding the phage T7 RNA polymerase and lipofected (Rose et al., 1991) using $10 \mu \mathrm{g}$ of pTM1 expression plasmids. For cotransfections of cyclins and kinase $10 \mu \mathrm{g}$ of each plasmid was used. Twenty-four hours after transfection cultures were lysed in MLB (25 mM morpholinepropanesulfonic acid, (pH 7.0), $250 \mathrm{~mm} \mathrm{NaCl}, 5 \mathrm{~mm}$ EDTA, $0.1 \%$ NP40. $1 \mathrm{~mm}$ DTT (dithiothreitol), $1 \mathrm{mg} / \mathrm{ml}$ aprotinin, $1 \mathrm{mg} / \mathrm{ml}$ leupeptin and $50 \mathrm{mg} / \mathrm{ml}$ phenylmethylsulfonyl fluoride) and clarified by centrifugation. Epitope tagged proteins were immunoprecipitated using EE antibody conjugated to agarose beads (5 mg EE antibody/ml of Affigel 10 (BRL, Gaithersberg, Maryland); 'anti-EE beads'). Samples were washed MLB, once in $50 \mathrm{~mm}$ Tris (pH 7.4)-1 mM DTT (TD) and eluted into $50 \mu \mathrm{l} \mathrm{TD}$ containing $0.1 \mathrm{mg} / \mathrm{ml}$ of the peptide cognate to the EE antibody (EEEEYMPME) and 20\% glycerol. $\mathrm{pRb}$ substrate was isolated similarly, omitting serum starvation and using immunoprecipitation with 12CA5 (anti HA) antibody for HA-tagged pRb. Lamin B was isolated from rat liver nuclear envelopes using a procedure outlined previously (Templeton et al., 1991).

Epitope tagged cyclin molecules were employed throughout the work, while kinase molecules were untagged. While potential alterations in conformation are possible in modified proteins, known activities of the cyclins/CDKs mirror the known properties of proteins monitored elsewhere. Additionally, the epitope tag approach affords the possibility of measuring enzyme activity without bound antibody, which may sterically alter activity. 
For substrate isolated from bacteria either $\mathrm{pRb}-\mathrm{GST}$ or lamin B 5'EE pET were expressed in BL21 bacteria. Lamin B $5^{\prime} \mathrm{EE}$ pET was isolated according to the pET system manual from Novagen except that the cultures were induced with IPTG overnight. GST-Rb-LP was isolated as previously described (Ewen et al., 1993).

\section{In vitro kinase assays}

For assays with cyclin/CDK1, $2 \mu$ each of the cyclins was mixed with $8 \mu \mathrm{l} \mathrm{pRb}$ protein A slurry or with $0.5 \mathrm{mg} / \mathrm{ml}$ histone H1 (Sigma, St. Louis, MO) or with $4 \mu$ l nuclear envelopes in a final reaction mixture of $20 \mu \mathrm{l}$ containing

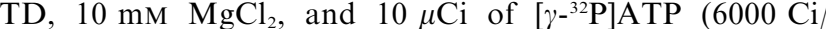
mmol) per reaction. Samples were run on $12.5 \%$ SDS PAGE, transferred to Immobilon-P filters (Millipore, Bedford, MA) and analysed by autoradiography and AMBIS quantification. For assays using cyclin/CDK2, $2 \mu \mathrm{l}$ of each of the cyclins was mixed with $0.5 \mathrm{mg} / \mathrm{ml}$ histone $\mathrm{H} 1$ in a final reaction mixture of $20 \mu \mathrm{l}$ as described above. For all further in vitro kinase assays equivalent amounts of cyclin/CDK2 histone kinase activities (as measured by AMBIS) were used to normalize reactions. Dilutions of the cyclin/kinases made to achieve equivalent histone kinase activities are as follows: Cyclin A-no dilution, cyclin E-1.5 dilution, cyclin AEE-no dilution, cyclin EAA-2.0 dilution. $2 \mu \mathrm{l}$ of each of these dilutions were mixed with $0.5 \mathrm{mg} / \mathrm{ml}$ histone $\mathrm{H} 1$ or $0.5 \mathrm{mg} / \mathrm{ml} \mathrm{pRb}$-large pocket-GST or $0.05 \mathrm{mg} / \mathrm{ml}$ lamin $\mathrm{B}$ in a final reaction mixture of $20 \mu \mathrm{l}$ as described above. In vitro kinase time course assays using the cyclin/CDK1 complexes were performed as above using $0.5 \mathrm{mg} / \mathrm{ml}$ histone $\mathrm{H} 1 \mathrm{sampling}$ at $30 \mathrm{~s}, 1 \mathrm{~min}, 2 \mathrm{~min}, 5 \mathrm{~min}$ and $10 \mathrm{~min}$ after radiolabel addition. In vitro kinase time course assays using the cyclin/CDK2 complexes were performed as above using either $0.5 \mathrm{mg} / \mathrm{ml} \mathrm{pRb}-L P-G S T$ or $0.05 \mathrm{mg} / \mathrm{ml}$ lamin B-5'EE sampling at $1 \mathrm{~min}, 2 \mathrm{~min}$, $5 \mathrm{~min}, 10 \mathrm{~min}$ and $30 \mathrm{~min}$ or $0.5 \mathrm{mg} / \mathrm{ml}$ histone $\mathrm{H} 1$, sampling as above.

\section{Western blot analysis}

Radioactive samples transferred to Immobilon-P were subjected to immunoblot analysis. After quantification by AMBIS, HA-tagged $\mathrm{pRb}$ were detected with $12 \mathrm{CA} 5$ ascites (anti HA). To confirm cyclin expression and kinase binding, $10 \mu \mathrm{l}$ of the original $50 \mu \mathrm{l}$ cyclin/kinase eluate was run on a $12.5 \%$ SDS-PAGE and transferred to Immobilon-P. The cyclins were detected using anti-EE ascites, CDK1 was detected using a monoclonal antibody to CDK1 (Cell Biology Products, GIBCO-BRL, Gaithers-

\section{References}

De-Bondt HL, Rosenblatt J, Jancarik J, Jones HD, Morgan DO and Kim SH. (1993). Nature, 363, 595-602.

Desai D, Wessling HC, Fisher RP and Morgan DO. (1995). Mol. Cell. Biol., 15, 345-350.

Ducommun B, Brambilla P, Felix M-A, Franza Jr BR, Karsenti E and Draetta G. (1991). EMBO J., 10, $3311-$ 3319.

Dulic V, Lees E and Reed SI. (1992). Science, 257, 1958 1961.

Dynlacht BD, Glores O, Lees JA and Harlow E. (1994). Genes Dev., 8, $1772-1786$.

Elledge SJ, Richman R, Hall FL, Williams RT, Lodgson N and Harper JW. (1992). Proc. Natl. Acad. Sci. USA, 89, $2907-2911$.

Elledge SJ and Spottswood MR. (1991). EMBO J., 10, $2653-2659$ berg, MD) and CDK2 was detected using a polyclonal antibody against CDK2 (Upstate Biotechnology Incorporated, Lake Placid, NY)

\section{CDK1 co-immunoprecipitation}

CV1 cells were infected/transfected as above with $5 \mu \mathrm{g}$ plasmid DNA encoding untagged CDK1, CDK1 plus cyclin A or cyclin $\mathrm{E}$, or CDK1 plus CDK2 and cyclin A or cyclin E. Twenty-four hours after lipofection cells were lysed in MLB as above. Lysates were clarified by centrifugation and $1 \%$ of the lysate removed to confirm equivalent expression of CDK1 resulting from all transfection. The tagged proteins were immunoprecipitated using anti-EE beads as above. Samples were washed four times in $1 \times$ MLB, once in $50 \mathrm{~mm}$ Tris $(\mathrm{pH} 7.4)-1 \mathrm{~mm}$ DTT (TD) and the proteins were eluted into $50 \mu \mathrm{l}$ TD containing $0.1 \mathrm{mg} / \mathrm{ml}$ of the peptide cognate to the EE antibody (EEEEYMPME). Samples were then run on $12.5 \%$ SDSPAGE, and after electrophoresis transferred to Immobilon$P$ filters (Millipore). The presence of co-immunoprecipitated CDK1 was visualized using a monoclonal antibody to CDK1 (Cell Biology Products, GIBCO-BRL, Gaithersberg, MD)

\section{Phosphatase treatment}

CDK1 kinase isolated as described above was treated for $30 \mathrm{~min}$ in kinase buffer either with or without 25000 units of bacterially produced PTPB1 (a gift of Gary Landreth, CWRU) at room temperature. After the 30 min incubation $1 \mathrm{mM}$ sodium vanadate, $10 \mathrm{mM}$ PNPP, $10 \mu \mathrm{Ci}\left[\gamma^{32}\right.$-P $]$ ATP and $0.5 \mathrm{mg} / \mathrm{ml}$ histone $\mathrm{H} 1$ were added to each reaction and incubated for $10 \mathrm{~min}$ at room temperature. Samples were run and analysed on $12.5 \%$ SDS-PAGE and autoradiography.

\section{Acknowledgements}

We thank Yongyi Qian and Margaret Lewis for technical assistance, Dr Malathy Mahalingam, Dr Joe Deak and Minhong Yan for helpful discussions and Fred Moeslein for critical reading of the manuscript. We also thank Mike Myers and Dr Gary Landreth for their gift of PTP1B and help with the phosphatase assay. We also thank Dr Alan Fields and Dr Bill Kaelin for providing useful clones and reagents. This work was supported by Grant CA-55719 from the NIH. LEH was supported by an NIH training grant to the Cell and Molecular Biology Program at Case Western Reserve University.

Elroy-Stein O, Fuerst T and Moss B. (1989). Proc. Natl. Acad. Sci. USA, 86, 6126-6130.

Ewen ME, Sluss HK, Sherr CJ, Matsushime H, Kato J-Y and Livingston DM. (1993). Cell, 73, 487-497.

Fang F and Newport JW. (1991). Cell, 66, 731-742.

Girard F, Struasfeld U, Fernandez A and Lamb NJC. (1991). Cell, 67, 1169-1179.

Hinds PW, Mittnacht S, Dulic V, Arnold A, Reed SI and Weinberg RA. (1992). Cell, 70, $993-1006$.

Horton LE, Qian Y and Templeton DJ. (1995). Cell. Growth Diff., 6, 395-407.

Hunt T. (1989). Curr. Op. Cell. Biol., 1, $268-274$.

Hunt T. (1991). Semin. Cell. Biol., 2, 213-222.

Jeffrey P, Russo A, Polyak K, Gibbs E, Hurwitz J, Massague J and Pavletich N. (1995). Nature, 376, 313-320. 
Kobayashi H, Stewart E, Poon R, Adamczewski JP, Gannon J and Hunt T. (1992). Mol. Biol. Cell, 3, 1279-1294.

Koff A, Cross F, Fisher A, Schumacher J, Leguellec K, Philippe M and Roberts JM. (1991). Cell, 66, 1217-1228.

Koff A, Giordano A, Desai D, Yamashita K, Harper JW, Elledge S, Nishimoto T, Morgan DO, Franza BR and Roberts JM. (1992). Science, 257, $1689-1694$.

Lees EM and Harlow E. (1993). Mol. Cell. Biol., 13, $1194-$ 1201.

Marshall CJ. (1994). Nature, 367, 24.

McKeon F. (1991). Curr. Op. Cell. Biol., 3, 82-86.

Moss B, Elroy-Stein O, Mizukami T, Alexander WA and Fuerst TR. (1990). Nature, 348, $91-92$.

Naysmith K. (1993). Curr. Op. Cell Biol., 5, 166-179.

Nugent JH, Alfa CE, Young T and Hyams JS. (1991). J. Cell Sci., 99, 669-674.

Pagano M, Pepperkok R, Lukas J, Baldin V, Ansorge W, Bartek J and Draetta G. (1993). J. Cell. Biol., 121, $101-$ 111.

Pines J. (1993). Trends Biochem. Sci., 18, 195-197.

Pines J and Hunter T. (1991). Trends Cell Biol., 1, 117-121.

Pines J and Hunter T. (1994). EMBO J., 13, 3772-3781.

Qian Y, Luckey C, Horton L, Esser M and Templeton DJ. (1992). Mol. Cell. Biol., 12, 5363-5372.

Quelle DE, Ashmun RA, Shurtleff SA, Kato J-Y, Bar-Sagi D, Roussel MF and Sherr CJ. (1993). Genes Dev., 7, $1559-1571$.

Resnitzky D, Gossen M, Bujard H and Reed SI. (1994). Mol. Cell. Biol., 14, 1669-1679.
Resnitzky D, Hengst L and Reed SI. (1995). Mol. Cell. Biol., $\mathbf{1 5}, 4347-4352$.

Rose JK, Buonocore L and Whitt MA. (1991). BioTechniques, 10, $520-525$

Rosenblatt J, Gu Y and Morgan DO. (1992). Proc. Natl. Acad. Sci. USA, 89, 2824-2828.

Roy LM, Swenson KI, Walker DH, Gabrielli BG, Li RS, Piwnica-Worms H and Maller JL. (1991). J. Cell. Biol., 113, $507-514$.

Sarkar G and Sommer SS. (1990). Biotechniques, 8, 404407.

Sherr CJ. (1993). Cell, 73, 1059- 1065.

Solomon MJ. (1993). Curr. Op. Cell. Biol., 5, 180-186.

Taylor SS, Knighton DR, Zheng J, Sowadski JM, Gibbs CS and Zoller MJ. (1993). Trends Biochem. Sci., 18, 84-89.

Templeton DJ. (1992). Mol. Cell. Biol., 12, 435-443.

Templeton DJ, Park SH, Lanier L and Weinberg RA. (1991). Proc. Natl. Acad. Sci. USA, 88, 3033-3037.

Tsai L, Lees F, Faha B, Harlow E and Riabowol K. (1993). Oncogene, 8, 1593-1602.

Uchida S, Sekiguchi T, Nishitani H, Miyauchi K, Ohtsubo $\mathrm{M}$ and Nishimoto T. (1990). Mol. Cell. Biol., 10,577-584.

Wang Y and Prives C. (1995). Nature, 376, 88-91.

Zhang F, Robbins DJ, Cobb MH and Goldsmith EJ. (1993). J. Mol. Biol., 233, 550-552.

Zheng J, Knighton DR, ten Eyck LF, Karlsson R, Xuong N, Taylor SS and Sowadski JM. (1993). Biochemistry, 32, $2154-2161$. 